\title{
DEVELOPING A PRACTICE OF AFRICAN-CENTRED SOLIDARITY IN CHILD AND YOUTH CARE
}

\author{
Peter Amponsah and Juanita Stephen
}

\begin{abstract}
What does it mean to be an ally? More specifically, what does it mean to do the work of allyship in support of Black young people and families? As educators, researchers, and practitioners in the child and youth care field, we seek to initiate a conversation pertaining to the epistemological make-up of child and youth care practice and the movement towards persistent and intentional solidarity work as a framework for cross-racial engagement. Through a series of critical questions, this paper seeks to deconstruct the taken-for-granted practices of White Eurocentric allyship in favour of a new vision for the future of solidarity work with African-descended children, youth, and their communities.
\end{abstract}

Keywords: African-centred, solidarity work, allyship, critical youth work, decolonial practice

\begin{abstract}
Authors' note: This paper is based on the panel presented at the Child \& Youth Care in Action VI Conference: Moving Through Trails and Trials Toward Community Wellness, held in Victoria, British Columbia, Canada at the University of Victoria, April 25th to 27th, 2019. The panel included the present authors as well as Dr. Julian Hasford and Travonne Edwards. Their thinking and theorizing was crucial to the panel and have been influential in the development of this paper. We are also grateful to Dr. Johanne Jean-Pierre for including us in the development of the panel.
\end{abstract}

Peter Amponsah MSW (corresponding author) is a PhD student in Social Work at York University, Keele Campus - Room S880, Ross Building, 4700 Keele St., Toronto, ON M3J 1P3. Email:pamponsa@yorku.ca

Juanita Stephen MA is a PhD student in Gender, Feminist \& Women's Studies at York University, Keele Campus - Room 206G, Founders College, 4700 Keele St., Toronto, ON M3J 1P3. Email: jstephen@yorku.ca 
International Journal of Child, Youth and Family Studies (2020) 11(2): 6-24

...the weather is the totality of our environments; the weather is the total climate; and that climate is antiblack.

Christina Sharpe (2017, p. 104)

Black people do not need allies. We need people to stand up and take on the problems borne of oppression as their own, without remove or distance. We need people to do this even if they cannot fully understand what it's like to be oppressed for their race or ethnicity, gender, sexuality, ability, class, religion, or other marker of identity. We need people to use common sense to figure out how to participate in social justice.

Roxane Gay (2016, para. 12)

What does it mean to be an ally? More specifically, what does it mean to do the work of allyship in support of Black young people and families? These questions relate to child and youth care's ongoing professional, moral, and ethical quest to do better work with marginalized young people and communities. These questions, and many related ones, have gained considerable attention in social justice discussions over the last decade, and more recently in child and youth care literature, education, and practice (de Finney et al., 2018; Gharabaghi, 2017; Munroe, 2017; Saraceno, 2012; Skott-Myhre, 2017). This results, in part, from the continually unfavorable outcomes seen in the cases of young people served by child and youth care and the uncompromising environments in which child and youth care takes place. These are compounded by sustained political and social disregard for child and youth matters, and the global and national momentum towards more empirically based, and control-oriented strategies of care

As Issitt and Spence (2005) have noted, "In the contemporary climate ... the language of both accreditation and so-called smart outcomes (specific. measurable, achievable, realistic, timed) with their promises of measurable and completed results seems to have robbed youth work of its ability to express and explain itself on its own terms and in its own more subtle vocabulary" (p. 64). These dynamics have culminated in the need for child and youth care to push back against the influences of trends that impact the field's ability to have intentional responses to Black/African youth's experiences.

The authors of this paper are practitioners, educators, and researchers in the child and youth care field who have experience in both their personal and professional lives with matters of allyship. For both, their encounters and engagement with ally work, literature, interpersonal moments, and institutional arrangements have, for the most part, been grounded in Whiteness. That is, White racial experience is the lens through which possibilities and limitations for different social relations are discussed and acted upon. This approach normalizes Whiteness as the entry point into goodness, understanding, and change, and poses many challenges for the field of child 
and youth work by contributing to the maintenance of a stagnant space of practice amidst rigid concepts of care. One example of such an outcome is the depoliticized and dehistoricized content that is taught in child and youth care curriculums, which ignores the importance of historically constituted sociopolitical realities. A general scan of publicly available course outlines will present some surprising and disappointing facts on the degree to which child and youth care is committed to allyship, particularly in regards to Black and Afro-diasporic children and youth's experiences.

Throughout this paper the authors use African and Black interchangeably. The authors acknowledge the histories of the terms African and Black as highly contested social, cultural, and historical phenomena. However, for the purposes of this paper, the author's draw on Mohanty and DeCoito (2009) who provide a guideline for the use and understanding of this language. Black is the political term used to categorize and define individuals who are of African descent whose ethnic or ancestral origins are in Africa. However, the diversity within the population requires the user of this terminology to be knowledgeable of and sensitive to the different cultural and linguistic groups within it (p. V).

The authors employ a decolonial perspective in tackling the issue of allyship and solidarity work with Black/African children, youth, and communities. To these ends, we draw from the decolonial project as proposed by Frantz Fanon in his early works (1952, 1963), which rejected the historical and current colonial order, including its racial relations, in favour of the "new being". That is, in the context of child and youth care, this paper seeks to subvert the taken-for-granted ideas about care work for Black children and youth in an attempt to propose a practice that affirms the existence and experiences of Black/African children and youth.

Much of the mainstream work on allyship has been led by White authors (Bishop, 2002; McIntosh, 2003; Wise 2005) whose writings are meant to speak to White audiences. Although these authors have added valuable concepts to the literature, they lack a critical lens to be able to interpret the deeply embedded role of race in determining, for instance, who bears the burden of proof for racially unjust experiences, a lens that can arguably only be developed through a firsthand lived experience of racial injustice. Far too often the power of racial burden is ignored in these writings (Bonilla-Silva, 2012; Froyum, 2013), and, as is experienced in the daily dynamics of racial inequity, it is up to racialized scholars to challenge and expand our ideas of what is and isn't possible in transformative youth work and social relations. Our hope is to add to this call for voices and open up the conversation by drawing upon Black and African-centred worldviews.

Our efforts to expand the dialogue in the child and youth care field, however, have been met with varied responses, especially concerning anti-Black racism work. Similar to those identified by Bishop (2002), these responses from child and youth care professionals and institutions can be characterized under three themes pertaining to the field: resistance, acceptance, and denial:

- Resistance: This response is rooted in a sense of entitlement to the power of providing care. McKamey (2017) brought light to this point in her piece exploring care education. She said, 
International Journal of Child, Youth and Family Studies (2020) 11(2): 6-24

"in caring towards, the carer maintains power over the cared for" (p. 214). She went on to say:

In one form of caring for - the caring towards discourse — the youth worker maintains their own cultural norms or perspective. Sometimes the youth worker acts on behalf of the appropriate rules expected within the school or educational context. The youth worker acts upon what they view is in the best interest of the young person. (p. 214)

- Acceptance: Often displayed by those who cannot see the potential of child and youth care or social inequity to be transformed. This is seen in the hesitancy to have child and youth care education engage with alternative pedagogies and voices in favour of solidifying its professional identity and mandate. This response is challenged by creativity and innovation.

- Denial: Often displayed by those who refuse to see child and youth care work as a contentious, social-political space in favour of a self-indulgent benevolence. This is evidenced in the scarcity of attention directed towards structural dimensions of child and youth care work, such as the changing geopolitical context of young people today.

Such positions perpetuate harmful practices and pedagogies in the child and youth care field that require deep and intentional reflexive work to unravel. These include the appropriation of cultural tools and frameworks in our attempts to diversify child and youth care curriculums; the funnelling of racialized bodies into particular care roles in teaching and frontline practice; and the apathy directed to critical issues of disproportionality in various service systems.

As we move forward in this process of simultaneous deconstruction and construction, we ask the reader to be open. What might it look like to not be the expert on someone else's care needs? To honestly engage with the type of practice that you have been doing? Are you providing the outcomes you want or the outcomes that are needed? And, moreover, are the lives of the Black children and youth you serve changing for the better? We hope that the discussion we start here and the ongoing self-reflexive work you will do will help to answer these questions.

\section{Troubling the Notion of "Allyship"}

A key element in the foundation of this discussion is to consider what is meant by the word "ally". Some schools of thought embrace the idea of allyship as an identity, claiming that one can take up the title of "ally" based on an alignment with certain ideologies or by engaging in certain practices. Others conceptualize allyship as a practice, linked specifically - and exclusively — to action. The Anti-Oppression Network (n.d.) takes up this orientation, speaking of allyship as "an active, consistent, and arduous practice of unlearning and reevaluating, in which a person in a position of privilege and power seeks to operate in solidarity with a marginalized group" (para. 2). Though the authors of this paper tend to align more closely with the second understanding, we 
approach the word ally with some reservation, recognizing that the popularized use of the word brings with it certain assumptions, associations, and familiarities that are misaligned with the spirit of the work we aim to discuss. The growing use of the word in academic, activist, and popular discourse has shifted "allyship" from a topic of critical engagement to a buzzword that is invoked frequently but with little critical thought. This can be observed through the use of the word "ally" as common branding on T-shirts and buttons, usually backed by an image of a rainbow or another graphic meant to identify the social movement with which the wearer claims to be allied. Presumably, wearing the shirt or button is meant to be read as an act of allyship. Or, perhaps more generously, it can be understood as an act of communication - politically marking the wearer as someone choosing to be on the right side of history. While there is no way to know what actions the wearer engages in beyond this public self-identification, it leaves unanswered the question, "Who does this public declaration benefit?" Is it a signal that the bearer is "one of the good guys" or does it mean that they are open to being recruited to do the work that is implied by the title of ally? Similarly, when the ally paraphernalia is being handed out as swag at a college fair or sold on clearance at the local novelty store, how does that change how we think about what it means to call yourself an ally? The reality is that the title of ally can be claimed in this way with no further action. Yet we would argue that action — informed, persistent, deliberate action — is precisely what is missing from this expression of allyship, and, frequently, divorced from the word "ally" overall.

However, inaction is not the only way that allyship can become problematic. Actions can often impede or subvert the efforts put forth by oppressed groups toward impactful change. Uninformed allyship, for example, gives rise to action without awareness; that is, seeking to be helpful without doing the work of learning the history of not only the oppression, but also of the responses resistance, refusal, education, writing, calls to action - that have come before you. Uninformed allyship is problematic for several reasons. Primarily, in the case of allyship with Black communities, it devalues the work of the Black activists and scholars who have already done the work of framing the issues, identifying the actions taken, and (in many cases) outlining what responses are desired and appropriate for non-Black people who are committed to working for change. Secondarily, uninformed allyship centres the expertise of the ally and assumes that they will know best what is needed to address an issue that does not affect them directly. Informed allyship requires the work of listening across difference and centring the needs and wants of the Black communities allies aim to support, while uninformed allyship is motivated by an assumption that the ally will intuitively know what is needed and warranted in a particular situation.

Also problematic, performative allyship involves action that serves the ally more than the person or group the action is framed to be in support of. Performative allyship is done for the sake of being seen, often seeking recognition or exemption from inclusion in the oppressing (dominant) group. Performative allyship says, "See! I understand the issue and I vow to do better. Everyone look at me! White supremacy is an oppressive force, but I'm not like those White people. I am enlightened! I am different!" Publicly committing to working toward racial justice without doing 
the work is merely performative, as is donning ally buttons and T-shirts without doing the work required to dismantle systems of oppression. Consider who the public proclamations, tears, or retweets serve, and consider the possibility that the most significant beneficiary may be yourself. The posturing of allegiance in order to alleviate your own guilt or claim exemption from the "we" in "we need to do better" is not, in fact, allyship at all.

It is in instances such as these that we are reminded of the key role that language plays in framing our understanding and application of concepts and ideologies. While "ally" is frequently taken up as an identity or indicator of proximity to social justice issues, the word on its own does not imply action. This being so, the authors of this paper seek to trouble that language. We posit that in order to develop a child and youth care practice that is dedicated to centring the "empowerment, liberation, and well-being of people of African descent" (Hasford et al., n.d.), practitioners must use language that is congruent with the action to which they are committed. We put forth solidarity work as a reframing of allyship. Moving away from the language of identity, African-centred solidarity work refocuses on the type of action necessary to support Africandescended young people and families in care work. African-centred solidarity work is (a) specific in its focus - deliberately centring the needs, values, and voices of African-descended people; (b) relentless - persisting in spite of risk, fear, or ignorance; (c) intentional — requiring workers to recognize their racial, gender, class, and ability privilege and to leverage it for the benefit of African-descended people; and (d) manifest on multiple levels - personal, structural, political, and spiritual.

\section{Basic Tenets of African-Centred Solidarity Work}

\section{Epistemological Focus}

All professions have their epistemological stance; that is, the way they come to know, and what counts as knowledge. In the case of child and youth work specifically, this stance is rooted in the way we come to know ourselves as a profession that cares. It is through this stance that knowledge, information, ideas, and opinions are organized to form an identity and culture (Williams, 2006).

The North American brand of child and youth work has emerged from an environment of Eurocentrism that, therefore, informs much of the profession's epistemological direction. As a result, the opportunities and capacity to show authentic engagement with African-descended young people and their needs have been all but eliminated. A Eurocentric worldview, Amin (1989) explained, is concerned with the reproduction and imitation of the Western model by all people as the solution to our problems. He stated that, "Eurocentrism is a specifically modern phenomenon, the roots of which go back only to the Renaissance, a phenomenon that did not flourish until the nineteenth century. In this sense, it constitutes one dimension of the culture and ideology of the modern capitalist world" (p. vii). Taking Amin's point practically, we note that the timeline commonly put forward for the genesis of the professionalization of child and youth care practice in North America mirrors the timeline for the development of Eurocentricity (Charles \& Garfat, 
International Journal of Child, Youth and Family Studies (2020) 11(2): 6-24

2009). The relationship of the child and youth care profession to processes of nation-building continues to sustain the White perspective in the work; it is an area of inquiry that requires more critical exploration.

A careful examination of the tools that are used in the creation of knowledge in child and youth care will reinforce some key facts: (a) Knowledge creation happens as a part of multiple, historical, sociopolitical processes; (b) White, upper-middle class, European people (predominantly men) have controlled these processes; (c) These processes have been strategically constructed to benefit White, upper-middle class, European people at the expense of others, including non-European people. These facts have shown up in consistent ways through the texts, discourses, and ideological orientations found in many spaces of higher learning. It is this understanding that frames our need for shifting the intellectual and professional entry point for those who engage in care work with African-descended populations.

\section{Relentless Persistence}

As solidarity work focuses on centring the needs and well-being of people who are dissimilar to ourselves, it rarely comes naturally. Starting from a place of unfamiliarity can be daunting and can present challenges - fear. risk, ignorance — to our motivation to persist. However, inherent to the work of solidarity is encountering these challenges and labouring to overcome them. Black young people and their families may face issues that literally threaten their personal safety and human rights; these issues often necessitate solidarity with non-Black people. It is understandable that doing the work to address these issues and dismantle the systems that uphold them can be scary. Showing up at police headquarters, for instance, to demand accountability for the unnecessary use of lethal force on a Black man requires the use of the bodies of solidarity workers to stage a protest along with Black communities that have seen too many deaths, who have learned that at any time it could be a member of their own family whose life is not seen as valuable enough to spare. Aligning with Black bodies in this way can be fear-inducing, but solidarity work requires you to persist despite the fear.

Solidarity work also asks you to persist when you are not the expert. For example, if you are a teacher who is not familiar with any Black writers on the topics you are teaching during a particular semester, solidarity work asks you to use the resources available to you - the library, Google, and other print and online resources about Black scholars in that area of study — to educate yourself on how to bring Black voices into your classroom. Pay Black experts to come in as guest speakers. Become familiar with African ways of knowing. Claiming ignorance on "Black issues" shifts the responsibility onto Black people and their allies to do the work you refuse.

Finally, solidarity work requires you to persist even when it involves risk. The work of disrupting systems from which you may benefit, or from which your colleagues, friends, family, and professional network benefit, can bring real or imagined risk to your job security, income, personal and professional relationships, opportunities, or reputation. There are often incentives not to challenge the status quo - opportunities for advancement, greater earning potential, minimal 
conflict. However, we posit that true solidarity work requires action up until the point that you become as vulnerable as the group you are working in solidarity with. If you are working for equal pay, you must be willing to risk your income. If you are advocating for the hiring of more Black professors, you must be willing to persist, even when your own job security is threatened. The movement toward (and into) positions of vulnerability is as indicative of solidarity as the use of privilege or power that cannot be threatened, perhaps even more so.

We will use an Ontario-based community organization as an example. The Child and Youth Care Alliance for Racial Equity (CARE) was founded in 2017, bringing together educators, direct service practitioners, students, and young people — all of whom are Indigenous, Black, and people of colour (IBPOC). The collective formed in response to a noted absence of IBPOC representation in the field of child and youth care in particular, and in social services more broadly. Each of the dozen or so members of the collective had been working in their respective spaces - classrooms, communities, places of business - to challenge the exclusion and inequities they had come across. CARE served as a way to support and amplify those individual efforts through collaborative research, capacity-building, and activism. However, CARE's start-up was not seamless and was met with resistance and skepticism along the way. Many White practitioners expressed frustration at not being extended an invitation to membership since they claimed an orientation toward racial justice. Their public criticism of the organization's exclusion spread widely and quickly. Several IBPOC practitioners decided it was not in their best interest to be affiliated with a group committed to challenging institutions on racial injustice because of the potential impact on their job security and professional reputation. Others joined the collective, but were fearful that advocacy that was seen as "too much" or "too disruptive" could impact opportunities for their own professional advancement. This was a genuine space of fear, particularly for early-career practitioners and scholars. In fact, for the first year of CARE's existence, one member served as the point of contact for communication to the broader community in order that CARE's membership could be kept confidential, guarding against possible pushback directed at group members, some of whom were particularly vulnerable. Also, none of the members really knew what the entity was that they were building together. They did know that there was racial injustice that had to be addressed and that they were willing to do the work necessary to make some impact.

The writers of this paper are two of the original members of CARE. We can say that now, two years in, the threats to our personal and professional reputations still exist - particularly when we are challenging a policy or practice enacted by a claimed "ally". We run the risk of losing their support for the rest of the work that we do. There is still pushback from institutions who are invested in the oppressive systems from which they benefit. These institutions have longerstanding reputations than our grassroots organization, which is still in its infancy; the institutions could easily use their influence to make it very uncomfortable for us to work in the very small field that is child and youth care. Finally, we still do not position ourselves as experts in this work. We have, however, learned how to show up, build relationships, ask questions, and listen for the best way we can use the resources and skills available to address the issues at hand. The positive 
International Journal of Child, Youth and Family Studies (2020) 11(2): 6-24

impacts - progressive policy development, necessary structural changes, and knowledge production — validate the risk.

Solidarity work is not about perfection, nor about expertise or fearlessness, but rather about the willingness to persist with intentional action.

\section{Intentionality}

Competency and capacity both influence the possibilities for solidarity work. As a result of heavily cognitive-based approaches to the development of social justice practice, individuals often find themselves suspended among the spaces of knowing, doing, and ability, unable to decide how to implement theory they have learned, and therefore developing a conditioned response of apathy and stagnation towards common-sense justice. This inaction is antithetical to the very nature of child and youth care practice, which must be responsive to the needs of vulnerable, marginalized children and youth. The overall desired outcome of racial equity for children and youth in care work is put in a precarious state when it becomes too dependent upon criteria of knowing and doing. The litmus test of quality education systems and programs should be their commitment to true racial and social justice education and research; however, the constraints and limitations presented in the highly contested spaces of knowing (see Epistemological Focus) and the pace at which change is happening mean that the current demand for children and youth services cannot be met. In addition, the space of the knower and known relationship, particularly for White practitioners in relation to anti-Black racism advocacy, must transcend the rhetoric of accountability and ability (Tetreault, 2018) to envision a transformational solidarity work that challenges White comfort and racial apathy. Nonetheless, the question of "How can I use what I have in my solidarity work?" continues to be a persistent one that has not received sufficient attention.

A fundamental principle of solidarity work is the acknowledgement and understanding of one's privilege, particularly White privilege and its influences on one's subjectivity. A key, yet contested, principle in much social justice theorizing is the understanding of the expression of privilege and oppression as intersectional, contextual, omnipresent, and diversified (Hill Collins, 1990; Crenshaw, 1991). Given these contending but complementary stances, it would be useful to engage in exploring racial justice as an imperative (Hemphill, 2015; Szekeres et al., 2019) that requires moral courage. Kutlaca et al. (2019) tell us that "what differentiates acts of moral courage from other pro-social behaviors is ... the underlying motivation to restore a violated moral standard" (p. 2). In other words, child and youth care's recognition of the inequities in care for Black children and youth as issues of ethical significance should be enough of a catalyst to prompt the field and its practitioners towards seeking alternative outcomes. The following sections will offer some critical thoughts on what African-centred solidarity can look like across personal, structural, political, and spiritual domains. 
International Journal of Child, Youth and Family Studies (2020) 11(2): 6-24

\section{Solidarity Work on Multiple Levels}

\section{Personal Solidarity}

Self-awareness and self-reflection are common frameworks used in social justice education. These frameworks incorporate the idea that understanding the construction of one's thoughts, feelings, actions, sensations, identity, and so on is necessary for working with others who are in need. The use of reflection and self-awareness holds a significant space in the child and youth care field. Ricks (2011) wrote about a curriculum she facilitated, stating:

The self component is viewed as the learner being able to examine and understand how the knowledge and the skill areas of self are relevant for them, how the knowledge of self will be integrated into what they already know, and how the skills for knowing and changing self will be evidenced in their child and youth care practice. (p. 5)

As a result of these hopes for aspiring practitioners, child and youth care curriculums have overemphasized the skill development of self-awareness through reflection assignments and tasks, without taking a critical approach to the nurturing of this skill. This process of self-discovery leaves the layers of embedded oppressive thought intact and unnoticed, in favour of a liberalized selfpresentation as good and noble. Ricks (2011) aptly noted:

In spite of self being an amorphous concept, many professions and trainers of professionals argue that being one self and having self-awareness is critical in professional practice. The claim usually made is that more self-present and aware professionals are more effective. (p. 6)

In crafting an alternative approach to this skill development for effective African-centred solidarity, Mary Ellen Kondrat (1999) offered a way to think about our desired outcomes for practitioners. She identified three different types (or levels) of awareness that are commonly found in social justice literature: "(a) simple conscious awareness (awareness of whatever is being experienced), (b) reflective awareness (awareness of a self who is experiencing some-thing), and (c) reflexive awareness (the self's awareness of how his/her awareness is constituted in direct experience)" (p. 451). Child and youth care, like many related professions, has suffered from the absence in its pedagogy of critical reflexivity; that is, a framework of reflection that allows practitioners to acknowledge and deconstruct the historical, sociopolitical power structures and mechanisms that have contributed to the current issues of inequity for children and youth. As Jan Fook (2015) stated, "In order to be reflexive, we need to be aware of the many and varied ways in which we might create, or at least influence, the type of knowledge we use" (p. 443). Fook's point further highlights the need for child and youth care practice to actively engage in revisiting and constructing new perspectives about who we really are, whom we are serving, and how we come to know our practice. Our field cannot claim to have been effective in Black children and youth's lives while Black parents and communities continue to experience multiple contexts of injustice. 
International Journal of Child, Youth and Family Studies (2020) 11(2): 6-24

There have been many critiques of the self-awareness, critical-reflection approach to personal and professional development for racial solidarity work. Heron (2005), though in favour of the use of reflection in educating critical practitioners, noted in an example:

The acknowledgment of privilege seems to strike a chord for racially aware members of the dominant group, but I would propose that admitting one's privilege does not necessarily unsettle its operation. For this is a concept that has the potential to leave those who name it in a place of double comfort: the comfort of demonstrating that one is critically aware, and the comfort of not needing to act to undo privilege. For individuals on the other side of the privilege coin, the citing of privilege by those in dominance amounts, however inadvertently, to a reinscription of marginalization. (p. 344)

Badwall (2016) took a similar stance. She was "concerned with the ways in which critical reflexivity is at risk of operating as a tool of governance and regulation" (p. 1). She went on to state that "the practice of critical reflexivity works to re-install whiteness through the colonial production of moral superiority and innocence" (p. 1). Reflective processes that ignore the practitioner's relationship to the land that they and the young people they serve occupy, along with the historically constituted social relations at present, can be detrimental to the advancement of racial justice for equity-seeking groups.

In child and youth care practice, an effective posture for personal solidarity on issues of antiBlack racism is one that assumes a transformation-focused, critically reflexive stance. Such a stance would encourage professionals to situate themselves, their practice, and the young people they are working with within the larger White hegemonic infrastructures of society. Such a stance would provide the tools and language necessary to disrupt discourses and initiatives associated with unfavourable outcomes for Black children and youth. Such a stance could help establish what the child and youth care profession's role is in seeking justice and reconciliation for racialized young people and communities.

\section{Political and Structural Solidarity}

In 1995 Mike Harris was elected premier of Ontario in a majority government. Harris and the Conservatives had run on a "Common Sense Revolution" platform (Bradburn, 2018) with the objective of minimizing bureaucracy and reducing the fiscal deficit. In the Conservative view, social programs and supports, including public education, were to blame for the province's financial woes; as a result, they made drastic cuts to those services. These actions had a direct impact on the province as a whole, but were particularly devastating in schools and communities that were already underresourced, many of which were home to Black children and youth (Price, 2018; Morgan, 2018).

On June 7, 2018, the province of Ontario elected another Conservative majority, with Doug Ford as its 42 nd premier. The Conservatives had again campaigned on and charted a path towards 
balancing the budget by eliminating and making cuts to social programs and education. One action that was widely seen as tragic and socially irresponsible was the elimination of the Office of the Provincial Advocate for Children and Youth (Syed, 2019), a nonpartisan political entity whose mandate was to oversee the well-being of children and youth and lobby the government for system changes. As Black children and youth are overrepresented in many of the social service programs and institutions that fell under the purview of the Advocate's office (e.g., child welfare and youth legal custody), the consequences of this action were notably detrimental for these young people. The Conservatives cut off one of the very few avenues Black children and youth had for seeking justice regarding discrimination and rights violations.

These two stories of political change share many similarities, but there is one obvious difference. Both stories highlight the ways that political ideologies can affect broader social outcomes. They have similar protagonists — White, male, Conservative premiers — and both illustrate how the outcomes of political decisions impact the lives of marginalized young people. The obvious difference between these stories is their timing. With 23 years separating the two eras of political governance, it appears that the lessons from the inequity and frustration felt in Black communities from one era have carried over to the next, highlighting the need for child and youth care to play an active role in neutralizing the political landscape that Black children, youth, and their "allies" have to navigate.

The question that child and youth care practitioners must take up is, "How can my practice reflect solidarity with Black children and youth, their families, and their communities at a political and structural level?" Some authors in child and youth care call for a radical, politicized practice in the work (Edwards \& Gaidhu, 2018; Gharabaghi, 2012; Skott-Myhre, 2017). For the purposes of broadening this discussion, we will draw from literature in the education field. Garad (2013), in comparing traditional approaches of care to Black Feminist or womanist epistemological approaches to care, stated that successful Black women educators display such a radical, politicized approach, "caring for students in a manner that resembles mothering, sometimes with tough love. This approach is more political than Eurocentric or white feminist caring because caring has more critical implications in marginalized communities" (p. 68). Garad (2013) went on to highlight that in the context of schools, "caring means enacting a political clarity: teaching students about and preparing them for the harsh realities of racism, sexism, and other 'isms' that exist beyond the schoolhouse" (p. 68). Drawing from this, we propose that child and youth care must reconstruct its approach to care work for Black children and youth to enact, throughout our field, the kind of political clarity identified by Garad (2013).

Political clarity asks child and youth care practitioners to consider how politics enter the institutions they are a part of, and how political ideologies are upheld through the mechanisms of that institution - the hiring practices, program requirements, eligibility criteria, curriculum, evaluation, and so on. Politicized practice recognizes that the power brought into a role through race, class, education, gender, or other axes of privilege can be used to call attention to the institutional practices that uphold injustice. For example, tenured professors can sit on hiring 
International Journal of Child, Youth and Family Studies (2020) 11(2): 6-24

committees and actively work toward recruiting Black candidates for tenure-track positions or advocate for broader integration of African epistemologies into the curriculum. Boards of directors can actively seek out Black candidates for management positions. Political and structural solidarity requires that your efforts extend beyond interpersonal relationships or participation in movements during your personal time. It recognizes the need to hold institutions accountable for their role in upholding injustice and wherever and however possible use those institutions to work towards redress.

\section{Spiritual Solidarity}

It is evident that in care systems, resources go where a need is identified. With regard to spirituality in care work, some have brought attention to the fact that it is an entirely absent priority in child and youth development (Benson \& Roehlkepartain, 2008) and others have noted that it is a matter of resolve and of investment in equipping child and youth care workers with what is necessary (Kimball, 2008). There is a significant body of literature on religion, spirituality, and Black children and youth (Curry, 2010; Dancy, 2010; Garad, 2013), indicating the importance, relevance, and necessity of spirituality for identity and development in this group. Therefore, if the issue of engaging with Black/African spirituality in care spaces is simply a matter of resolve and worker preparation, it speaks to the glaring gaps in what the field has given priority to. Child and youth care's position in the lives of young people opens it up to possibilities for solidarity that other professions cannot access. As such, it is essential for the field to view engaging in spirituality as justice work in child and youth care, as a practice that aligns with the field's priorities of caring for the whole child.

The hesitancy to engage with Black/African spirituality in care work lies in the aforementioned issues of competency and capacity (see Intentionality above). However, it is necessary to recognize also the epistemological barriers and dualities that are hidden in child and youth care that continue to present the bodies, communities, practices, and beliefs of Black people as dark, infantile, pathological, and mythical. This site of struggle in the minds of child and youth care workers must be interrogated through an intentional process of decolonization; a starting place for many practitioners could be asking difficult questions such as "Why is there less value placed on knowledge and resources from Black communities?", "What am I fearful of?", "Is the source of this fear real?", "Have I always had this fear?", and "How can I work through this fear to support transformation in young Black people's lives?" This series of questions is critical to the awareness necessary for solidarity work with Black children and youth that recognizes spirituality as valuable.

In turning towards the incorporation of spirituality in child and youth care, a paradigm shift must be made towards rehumanizing the Black child; it is when the child is seen as human that spirit can dwell and flourish. It is well documented (McCabe et al., 1999; Washington et al., 2014) that systems have deliberately represented Black children and youth as dysfunctional, delinquent, and violent, all of which actively serve to dehumanize the population. This process also includes 
removal, isolation, and exclusion from collective life, denying the Black child the possibilities of logic and civility; engaging in this type of identity destruction in child and youth care is not only unjust, but ethically irresponsible. Little attention has been paid to a reciprocal result; that is, the dehumanization that also takes place in the practitioner when they are not acting in favour of protecting and preserving young Black lives. This space of "spirit-less" work requires more attention and theorizing, which could furnish insights regarding the direction that child and youth care has been taking.

Carving out a practice of spiritual solidarity for Black youth requires practitioners to move away from Westernized concepts of a homogeneous Black/African people, and Westernized interpretation of Indigenous African spiritual traditions as a dark, illogical, and incomprehensible spirituality (Tagwirei, 2017), to a recognition of the heterogeneous complexity of Black/African experience. Spiritual solidarity needs to move to a more pragmatic application of daily practices that reaffirm Black children and youth's lives as valuable and worthy of dignity. To these ends, it is important for care systems to be transparent about their ability to create spiritually affirming spaces and services for Black children and youth and to have the willingness and humility to engage with ethnic and culturally specific communities and leaders to co-create these realities for children and youth.

Effective spiritual solidarity work starts from a place of acknowledging colonialism's role in determining spiritual value and recognizing the Black child as a human entity, worthy of a quality life. It also recognizes the plurality within Black/African experiences and spiritual beliefs, and recognizes that the communities in which these Black/African children and youth exist possess all of the knowledge and resources to address their needs, and these should be leveraged in creating holistic care communities.

\section{Conclusion}

The framework that we have proposed for developing a child and youth care practice of intentional, informed, relentless solidarity with Black children, youth, and families, is just that a framework. Like many of the foundational concepts in child and youth care, we recognize the need for and encourage more theorizing to grow this discourse, broadening both the theoretical understanding and practical application of the ideas held therein. Necessarily, this will require a continued shift in our field away from resistance, acceptance, and denial and an intentional movement toward the action Audre Lorde (1984) suggested - that we "reach down into that deep place of knowledge inside [ourselves] and touch that terror and loathing of any difference that lives here. See whose face it wears. Then the personal as the political can begin to illuminate all our choices." (p. 113).

Sandrina de Finney and colleagues (2012) have called for an urgent "engagement with the perspectives of other communities ... who are ignored under a EuroWestern colonial paradigm that shapes the 'canon' of our field" (p. 143). It is through these processes of deep self-reflexive action 
and the significant integration of the contributions from Indigenous, Black, and otherwise racialized educators, practitioners, and students that we may broaden and reconstruct - if we do not dismantle entirely - the canon of literature that informs and limits what child and youth care practice can and should be.

We are hopeful. Child and youth care as a discipline can only benefit from broadening the possibilities of practice and engagement with truly diverse perspectives and approaches. Only then can we say that we are truly foregrounding the interests and well-being of the Black children, youth, and families whom we claim to support. 
International Journal of Child, Youth and Family Studies (2020) 11(2): 6-24

\section{References}

Amin, S. (1989). Eurocentrism . Monthly Review.

The Anti-Oppression Network. (n.d.). Allyship. Retrieved from https://theantioppressionnetwork.com/allyship/

Badwall, H. (2016). Critical reflexivity and moral regulation. Journal of Progressive Human Services, 27(1), 1-20, doi:10.1080/10428232.2016.1108169

Benson, P., \& Roehlkepartain, E. (2008). Spiritual development: A missing priority in youth development. New Directions for Youth Development, 5, 13-28. doi:10.1002/yd.253

Bishop, A. (2002). Becoming an ally: Breaking the cycle of oppression in people (2nd ed.). Fernwood.

Bonilla-Silva, E. (2012). The invisible weight of whiteness: The racial grammar of everyday life in contemporary America. Ethnic and Racial Studies, 35(2), 173-194. doi:10.1080/01419870.2011.613997

Bradburn, J. (2018, June 6). In the mood for cuts: How the 'Common Sense Revolution' swept Ontario in 1995. TVO. Retrieved from https://www.tvo.org/article/in-the-mood-for-cuts-howthe-common-sense-revolution-swept-ontario-in-1995

Charles, G., \& Garfat, T. (2009). Child and youth care practice in North America: Historical roots and current challenges. Relational Child and Youth Care Practice, 22(2), 17-28.

Crenshaw, K. (1991). Mapping the margins: Intersectionality, identity politics, and violence against women of color. Stanford Law Review. 43(6): 1241-1299. doi:10.2307/1229039

Curry, J. (2010). Addressing the spiritual needs of African American students: Implications for school counselors. The Journal of Negro Education, 79(3), 405-415.

Dancy, T. (2010). Faith in the unseen: The intersection(s) of spirituality and identity among African American males in college. The Journal of Negro Education, 79(3), 416-432.

de Finney, S., Cole Little, JN., Skott-Myhre, H., \& Gharabaghi, K. (2012). Conversations on conversing in child and youth care. International Journal of Child, Youth \& Family Studies, 3(2-3), 128--145. doi:10.18357/ijcyfs32-3201210862

de Finney, S., Palacios, L., Kaur Mucina, M., \& Chadwick, A. (2018). Refusing band-aids: Unsettling "care" under the carceral settler state. CYC-Online, 235, 28-38.

Edwards, T., \& Gaidhu, A. (2018). Child and youth care — The enhancement of praxis: Theory to practice or theory vs practice? CYC-Online, 228, 36-45. 
International Journal of Child, Youth and Family Studies (2020) 11(2): 6-24

Fanon, F. (1952). Black skin, white mask. Grove.

Fanon, F. (1963). The wretched of the earth. Grove Weidenfeld.

Fook, J. (2015). Reflective practice and critical reflection. In J. Lishman (Ed.), Handbook for practice learning in social work and social care: Knowledge and theory (pp. 440-454). Jessica Kingsley.

Froyum, C. (2013). 'For the betterment of kids who look like me': Professional emotional labour as a racial project. Ethnic and Racial Studies, 36(6), 1070-1089. doi:10.1080/01419870.2011.644309

Garad, B. H. (2013). Chapter 3: Spiritually centered caring: An approach for teaching and reaching Black students in suburbia. Counterpoints, 454, 66-80.

Gay, R. (2016, July 11). On making black lives matter. marie claire. Retrieved from https:/www.marieclaire.com/culture/a21423/roxane-gay-philando-castile-alton-sterling/\#

Gharabaghi, K. (2012). The case for rebels. CYC-Online, 161, 16-19.

Gharabaghi, K. (2017). Why are we so white? CYC-Online, 220, 6-11.

Hasford, J,. Amponsah, P., Edwards, T., \& Stephen, J. (In final review). Anti-Black-racism and child and youth care praxis. In K. Gharabaghi and G. Charles (Eds.), Child and Youth Care Across Sectors.

Hemphill, B. (2015). Social justice as a moral imperative.The Open Journal of Occupational Therapy, 3(2), Article 9. doi:10.15453/2168-6408.1150

Heron, B. (2005). Self-Reflection in critical social work practice: Subjectivity and the possibilities of resistance. Journal of Reflective Practice, 6(3), 341-351. $\underline{\text { doi: } 10.1080 / 14623940500220095}$

Hill Collins, P. (1990). Black feminist thought : Knowledge, consciousness, and the politics of empowerment. Unwin Hyman.

Issitt, M., \& Spence, J. (2005). Practitioner knowledge and the problem of evidence based research policy and practice. Youth \& Policy, 88, 63-82.

Kimball, E. M. (2008). Spiritual development in youth worker preparation: A matter of resolve. New Directions for Youth Development, 118, 111-114. doi:10.1002/yd.264

Kondrat, M. E. (1999). Who is the "self" in self-aware: Professional self-awareness from a critical theory perspective. Social Service Review, 73(4), 451-477. doi:10.1086/514441 
International Journal of Child, Youth and Family Studies (2020) 11(2): 6-24

Kutlaca, M., Becker, J., \& Radke, H. (2019). A hero for the outgroup, a black sheep for the ingroup: Societal perceptions of those who confront discrimination [Online corrected proof]. Journal of Experimental Social Psychology, 103832. doi:10.1016/j.jesp.2019.103832

Lorde, A. (1984). The master's tools will never dismantle the master's house. In A. Lorde, Sister Outsider: Essays and Speeches (pp. 110-114). Crossing Press.

McCabe, K., Yeh, M., Hough, R. L., Landsverk, J., Hurlburt, M. S., Culver, S. W., \& Reynolds, B. (1999). Racial/ethnic representation across five public sectors of care for youth. Journal of Emotional and Behavioral Disorders, 7(2), 72-82. doi:10.1177/106342669900700202

McIntosh, P. (2003). White privilege: Unpacking the invisible knapsack. In S. Plous (Ed.), Understanding prejudice and discrimination (pp. 191-196). McGraw-Hill.

McKamey, C. (2017). Learning and teaching to care for young people. Child \& Youth Services, 38(3), 209-230. doi:10.1080/0145935X.2017.1297226

Mohanty, S., \& Decoito, P. (2009). A social profile of the Black population in Peel region, 2006 [Online]. Social Planning Council of Peel. Retrieved from http://portraitsofpeel.ca/pdf/2006\%20Blacks\%20bcan\%20report.pdf

Morgan, A. (2018, April 23). Populism and racism in two Ontario elections [Online]. Canadian Centre for Policy Alternatives. Retrieved from https://www.policyalternatives.ca/publications/monitor/populism-and-racism-two-ontarioelections

Munroe, T. (2017). Enriching relational practices with critical anti-Black racism advocacy and perspectives in schools. Relational Child and Youth Care Practice, 30(3), 32-45.

Price, N. (2018, Aug.8). Toronto's history of gun violence: A vicious cycle of missteps, intransigence and bad policy. NOW. Retrieved from https://nowtoronto.com/news/gunviolence/

Ricks, F. (2011). Self-awareness model for training and application in child and youth care. CYC-Online, 147, 5-11.

Saraceno, J. (2012). Mapping whiteness and coloniality in the human service field: Possibilities for a praxis of social justice in child and youth care. International Journal of Child, Youth \& Family Studies, 3(2-3), 248-271. doi:10.18357/ijcyfs32-3201210869

Sharpe, C. (2017). In the wake: On blackness and being. Duke University Press.

Skott-Myhre, H. A. (2017). Seeking a pass: White supremacy and CYC. CYC-Online, 220, 1217. 
International Journal of Child, Youth and Family Studies (2020) 11(2): 6-24

Syed, F. (2019, April 1). Ontario child advocate wonders whether Doug Ford just made your children 'invisible again'. National Observer. Retrieved from https://www.nationalobserver.com/2019/04/01/news/ontario-child-advocate-wonderswhether-doug-ford-just-made-your-children-invisible

Szekeres, H., Halperin, E., Kende, A., \& Saguy, T. (2019). The effect of moral loss and gain mindset on confronting racism. Journal of Experimental Social Psychology. 84, 1-15. doi:10.1016/j.jesp.2019.103833

Tetreault, L. (2018) "We're asking you to show up": Accountability as rhetorical practice for queer, feminist, and racial justice allyship (Doctoral dissertation). University of Louisville, Louisville, KY. doi:10.18297/etd/2982

Tagwirei, C. (2017). The "horror" of African spirituality. Research in African Literatures, 48(2), 22-36. doi:10.2979/reseafrilite.48.2.03

Washington, A. R., Byrd, J., Booth, J., \& Henfield, M. S. (2014). "Boxed in" Black. In V. E. Evans-Winters, \& M. C. Bethune (Eds.), (Re)teaching Trayvon: Education for Racial Justice and Human Freedom [Youth, Media, \& Culture Series], (pp.119-132). Sense.

Williams, C. C. (2006). The epistemology of cultural competence. Families in Society: The Journal of Contemporary Social Services, 87(2), 209-220. doi:10.1606/1044-3894.3514

Wise, T. J. (2005). White like me: Reflections on race from a privileged son. Soft Skull. 